\title{
Tightly Centromere-Linked Gene (SPO15) Essential for Meiosis in the Yeast Saccharomyces cerevisiae

\author{
ELAINE YEH, ${ }^{1}+{\text { JOHN CARBON },{ }^{2} \text { AND KERRY BLOOM }}^{1 *}$ \\ Department of Biology, University of North Carolina, Chapel Hill, North Carolina $27514,{ }^{1}$ and Department of Biological \\ Sciences, University of California, Santa Barbara, California $93106^{2}$
}

Received 8 August 1985/Accepted 10 October 1985

\begin{abstract}
We used DNA fragments from the centromere regions of yeast (Saccharomyces cerevisiae) chromosomes III and XI to examine the transcriptional activity within this chromosomal domain. RNA transcripts were found 200 to 300 base pairs from the 250-base-pair centromere core and lie within an ordered chromatin array. No transcripts were detected from the functional centromere region. We examined the cellular function of one of these tightly centromere-linked transcripts, $(C E N 11) \mathrm{L}$, by disrupting the coding sequences in vivo and analyzing the phenotype of the mutant yeast cell. Diploids heterozygous for the (CEN11)L disruption sporulated at wild-type levels, and the absence of the $(C E N 11) \mathrm{L}$ gene product had no effect on the viability or mitotic growth of haploid cells. Diploids homozygous for the $(C E N 11) L$ disruption were unable to sporulate when induced by the appropriate nutritional cues. The mutant cells were competent for intragenic recombination and appeared to be blocked at the mononucleate stage. The temporal ordering of (CEN11)L function with respect to the sporulation mutant spo13 suggests that the $(C E N 11) L$ gene product may be required at both the first and second meiotic cell divisions. This new sporulation gene has been termed SPO15.
\end{abstract}

The transmission of genetic material to progeny cells during the cell cycle is an essential process that proceeds with a high degree of precision in all eucaryotic organisms. This process involves the establishment of a spindle apparatus that interacts with specific regions along the eucaryotic chromosome, the centromeres, to direct the accurate segregation of identical genetic information to the daughter cells. Although yeast centromeres cannot be visualized at the morphological level, the genetic segregation properties of yeast chromosomes clearly indicate the involvement of specific chromosomal loci. The centromeric regions from five chromosomes in yeasts $(C E N)$ have been isolated (CEN3 [10], CEN4 [33], CEN5 [22], CEN6 [26], and CENII [14]) and are able to confer properties of chromosome stabilization and proper Mendelian segregation to replicating DNA molecules in yeasts (10). Furthermore, when CEN3 sequences are deleted from their host chromosome in vivo, an acentric chromosome is produced which is lost from the population, presumably owing to the missing spindle attachment site (11). The centromere sequence is therefore required to stabilize the entire yeast chromosome. Chromosome stability is recovered when the centromere DNAs from chromosomes III, XI, and VI are substituted in either orientation for the $C E N 3$ region in chromosome III $(3,11)$. The resulting chromosomes segregate normally through mitosis and meiosis in a manner identical to that of normal chromosome III. These results indicate that the yeast centromeres are fully functional in either orientation and are not necessarily chromosome specific.

The molecular organization of the centromere region of the chromosome is characterized by a conserved core particle that is surrounded by distinct arrays of nucleosomal subunits (4). The centromere core DNA is organized in a 220- to 250-base-pair (bp) chromatin particle that is protected from nuclease digestion in the cell nucleus. The structure of

\footnotetext{
* Corresponding author.

† Present address: CIBA-GEIGY Corp., Biotechnology Research, Research Triangle Park, NC 27709-2257.
}

the centromeric core particle is determined strictly by the centromere DNA sequence (5) and contains the conserved regions of DNA sequence homology between the different centromeres, elements I to III (reviewed by Carbon [7]). Deletion of these elements from the centromere region inactivates centromere function and coordinately disrupts the protected centromere core (5). In contrast, disruptions within the flanking centromeric regions show no deleterious effect on centromere function, and the flanking sequences do not have to be contiguous with the essential element I to III region for proper segregation of the host chromosome (8).

The function of the centromere in cellular processes may not be limited to its essential role in mitotic and meiotic cell divisions. The centromere region has been implicated in such events as elevated levels of mitotic recombination (16, $23)$, a suppression of meiotic recombination $(1,2,23)$, and variegation in gene expression (21). The distinctive nucleosomal array flanking the centromere may be involved in the structural organization of that region of the chromosome and may not have a direct role in centromere function. Alternatively, the flanking sequences may serve to prevent transcription through the centromere, since it has recently been shown that transcription initiated from a strong promoter and directed toward the $C E N$ sequences abolishes centromere function $(25 \mathrm{a}$; A. Hill and $\mathrm{K}$. Bloom, unpublished data).

The direct isolation of centromere DNA from the yeast Saccharomyces cerevisiae has made possible the isolation of sequences flanking the centromere. Hybridization studies reveal that these flanking sequences are not repeated in the yeast genome, although they may contain very small (10- to $50-\mathrm{bp})$ regions of homology $(4,10)$. We used cloned DNA fragments from around the centromere to characterize the transcriptional activity of the flanking centromere regions of chromosomes III and XI. RNA transcripts were detected from within the ordered nucleosomal arrays flanking CEN3 and $C E N 11$, and at least one of these transcripts is an essential meiotic gene, required for the reductional division in meiosis. 


\section{MATERIALS AND METHODS}

Strains. Escherichia coli JA226 (C600 hsd ${ }^{+} h s d R$ recBC lop-11 thi leuB6 $\mathrm{Str}^{r}$ ) and JA228 (W3110 $\operatorname{argH}$ hsdM ${ }^{+}$hsdR) were used for the transformation and amplification of plasmid DNAs. JM103 ( lac pro thi rpsL endA sbcBl5 hsdR supE $\mathrm{F}^{\prime}$ traD36 proAB lacI $\left.^{q} Z \Delta \mathrm{M} 15\right)$ was used in the M13 cloning. $S$. cerevisiae $\mathrm{X} 2180 \mathrm{a}$ was obtained from the Yeast Genetics Stock Center at the University of California, Berkeley. Strains LL20 (MAT $\alpha$ leu2-3,112 his3-11,15 ade2) and BF305-15d (MATa leu2-3,112 his3-11,15 adel arg5,6 trpl ura3-52 met 14) were obtained from Bruce Futcher. UNC1 is the diploid resulting from a cross between strains LL20 and BF305-15d. UNC1-2 was constructed by transformation of UNC1 with the DNA fragment containing the disrupted (CEN11)L region (see below). Homozygous disruptions were constructed by crossing the $\mathrm{F}_{1}$ progeny of UNC1-2.

Strains CG334 (MATa spol3-1 ade2 leul-c lys2-2 his7-1 met13-c tyrl-1 trp5-c chy ${ }^{\mathrm{R}}$ ), CG338 (MAT $\alpha$ spol3-1 ade2 leul-c lys2-1 his7-1 metl3-c tyrl-2 ura3-1 trp5-c $\mathrm{chy}^{\mathrm{R}}$ ), CG116 (MATa/MAT $\alpha$ HO/HO adelade2 canl $^{\mathrm{R}} /$ canl $^{\mathrm{R}}$ his311/his3-11 leul-12/leul-12 lys2-1/lys2-1 metl3-d/metl3-d trp5-d/trp5-d tyrl-1/tyrl-1 ura3-52/ura3-52), and CG127 (MATa/MAT $\alpha$ HO/HO ade2/ade2 his3-11,15/his3-11,15 leu23,112/leu2-3,112 lys2-1/lys2-1 trp5-20/trp5-20 ural/ural) containing $\operatorname{trp} 5$ heteroalleles were obtained from Craig Giroux. The (CEN11)L disruption strain UN4D (MATa/MAT spol5::HIS3/spol5::HIS3 his3-11,15/his3-11,15 trp5-20/trp5$d$ ade2/ade2 ural/URAI URA3/ura3-52 TYRI/tyrl-1 lys2I/lys2-1 leu2-3,112/leu2-3,112 leul-2/leul-2) and a wild-type strain UN3C5C (MATa/MAT $\alpha$ his3-11,15/his3-11,15 trp5d/trp5-20 URA3/ura3-52 metl3/MET13 tyrl-I/TYRI leul2/LEU1 leu2-3,112/leu2-3,112) were constructed to measure intragenic recombination.

Media. YPD medium contained $2 \%$ glucose, $2 \%$ peptone, and $1 \%$ yeast extract. Yeast minimal plates were made of $0.67 \%$ Difco yeast nitrogen base and $2 \%$ glucose, supplemented with $0.5 \%$ Casamino Acids (Difco Laboratories, Detroit, Mich.), adenine and uracil $(20 \mu \mathrm{g} / \mathrm{ml})$, and tryptophan $(50 \mu \mathrm{g} / \mathrm{ml})$. YPA medium contained $1 \%$ potassium acetate, $2 \%$ peptone, and $1 \%$ yeast extract. Sporulation medium consisted of $1 \%$ potassium acetate $(\mathrm{pH} 7)$. YPA and sporulation media were supplemented with the required amino acids $(50 \mu \mathrm{g} / \mathrm{ml})$. Plates contained $2 \%$ agar.

Plasmids. The following plasmids containing cloned DNA from the centromere region on chromosomes III and XI were used in the RNA mapping studies and for subsequent M13 cloning: from chromsome III, pYe(CDCI0)1 (10), $\mathrm{pYe}(C E N 3) 30$ (15), and $\mathrm{pYe}(C E N 3) \mathrm{B}$ (constructed by subcloning the 5.1-kilobase (kb) $B a m H I$ fragment from pYe46B2 [9] into the BamHI site in YRp7 [34a]), from chromsome XI, pYe(METI4)2 and pYe(CENII)5 (14). Specific restriction endonuclease DNA fragments were purified from agarose gels by electroelution as described by Maniatis et al. (24).

Preparation of RNA. $S$. cerevisiae RNA was prepared by the method of Reed et al. (28) with the following modifications. Yeast cells of the appropriate strain were grown at $32^{\circ} \mathrm{C}$ in YPD medium, harvested during the exponential growth phase $\left(10^{7}\right.$ cells per $\left.\mathrm{ml}\right)$, and washed once in water at $4^{\circ} \mathrm{C}$. Typically, $4 \times 10^{10}$ cells were lysed by being washed in REB buffer ( $0.1 \mathrm{M} \mathrm{LiCl,} 0.1 \mathrm{M}$ Tris hydrochloride [pH 7.5], $1 \mathrm{mM}$ EDTA) containing $0.5 \%$ sodium dodecyl sulfate (SDS) and $10 \mathrm{mM}$ iodoacetate (added immediately before use), resuspended in the same buffer, and stirred with glass beads in a Braun homogenizer. The resulting lysate was diluted with REB plus $1 \%$ SDS and $10 \mathrm{mM}$ iodoacetate and centrifuged at $4^{\circ} \mathrm{C}$. The $\mathrm{pH}$ was elevated in the supernatants by adding a 0.1 volume of $1 \mathrm{M}$ Tris hydrochloride $(\mathrm{pH} 9)$. Phenol-chloroform-isoamyl alcohol (50:49:1, vol/vol/vol) extractions were performed with equal volumes of organic and aqueous phases. The phases were separated by centrifugation. The first interface was reextracted with 0.5 volume of a buffer containing $0.1 \mathrm{M} \mathrm{NaCl}, 0.1 \mathrm{M}$ Tris hydrochloride $(\mathrm{pH}$ 9), $1 \mathrm{mM}$ EDTA, and 1\% SDS, and the aqueous phases were pooled. The extractions were repeated three times. The RNA was precipitated with 2 volumes of ethanol at $-20^{\circ} \mathrm{C}$ overnight. The RNA was collected by centrifugation, rinsed with $95 \%$ ethanol, dried, and suspended in $1 \mathrm{mM}$ EDTA ( $\mathrm{pH}$ 8 ). The concentration of nucleic acid was determined by the $A_{260}$.

Nuclear RNA was prepared from nuclei isolated as described by Bloom and Carbon (4). Isolated nuclei suspended in $1 \mathrm{M}$ sorbitol- $20 \mathrm{mM}$ piperazone-diethanesulfonic acid $(\mathrm{pH}$ 6.3) $-0.1 \mathrm{mM} \mathrm{CaCl} \mathrm{Cl}_{2}-1 \mathrm{mM}$ phenylmethylsulfonyl fluoride were adjusted to $1 \%$ SDS, and the $\mathrm{pH}$ was elevated by adding 0.1 volume of $1 \mathrm{M}$ Tris hydrochloride ( $\mathrm{pH} 9)$. The RNA was extracted and ethanol precipitated as described above.

Total RNA was also prepared from samples of $1 \times 10^{8}$ to $2.5 \times 10^{8}$ cells by a modification of the above procedure. Cells were lysed with glass beads in Eppendorf tubes after being vortexed six times for $20 \mathrm{~s}$ each time on a VortexGenie with intermittent cooling on ice. All buffers and extractions were as described above and were scaled down to volumes suitable for Eppendorf tubes.

Oligo(dT)-cellulose (type 2) from Collaborative Research, Inc. (Waltham, Mass.) was used according to the recommendations of the manufacturer.

Electrophoresis, transfer, and hybridization analysis of RNA. RNA was separated by size on $1.4 \%$ agarose-2.2 M formaldehyde gels in a buffer containing $40 \mathrm{mM}$ morpholinepropanesulfonic acid (MOPS) (pH 7.0), $5 \mathrm{mM}$ sodium acetate, and $1 \mathrm{mM}$ EDTA as modified from Maniatis et al. (24). The RNA was denatured in $50 \%$ formamide ( $\mathrm{pH}$ $>4.0)-2.2 \mathrm{M}$ formaldehyde ( $\mathrm{pH}>4.0)-40 \mathrm{mM}$ MOPS $(\mathrm{pH}$ 7) $-5 \mathrm{mM}$ sodium acetate-1 $\mathrm{mM}$ EDT A by incubation at $55^{\circ} \mathrm{C}$ for $15 \mathrm{~min}$, after which bromophenol blue and xylene cyanol were added. The RNA was electrophoresed at $90 \mathrm{~V}$ for $6 \mathrm{~h}$ and then transferred from the agarose gel to nitrocellulose paper (BA 85; Schleicher \& Schuell, Inc., Keene, N.H.) by the method described by Thomas (35).

Hybridization of nick-translated ${ }^{32} \mathrm{P}$-labeled DNA fragments (9) to RNA immobilized to nitrocellulose paper was done by the method of Cameron et al. (6). The hybridization buffer $(1 \times \mathrm{HYB})$ contained $0.5 \mathrm{M} \mathrm{NaCl}, 0.1 \mathrm{M}$ sodium phosphate buffer ( $\mathrm{pH} 7)$, and 6 mM EDTA. The blots were prehybridized for $2 \mathrm{~h}$ at $65^{\circ} \mathrm{C}$ in $1 \times \mathrm{HYB}$ plus $1 \% \mathrm{SDS}$. The ${ }^{32} \mathrm{P}$-labeled DNA probe was denatured by heating at $100^{\circ} \mathrm{C}$ for $5 \mathrm{~min}$, quick cooled on ice, and added to the hybridization solution. Hybridization was carried out overnight at $65^{\circ} \mathrm{C}$. The blots were washed in $0.25 \times$ HYB-1\% SDS for $1 \mathrm{~h}$ and then washed three times in $0.25 \times$ HYB with no SDS for $1 \mathrm{~h}$ each time. All washes were at $65^{\circ} \mathrm{C}$. The blots were air dried and exposed with Kodak XRP-5 film and a Du Pont Cronex Lightning-Plus intensifying screen at $-80^{\circ} \mathrm{C}$.

Transformation of yeasts. Yeasts were transformed by the lithium acetate procedure of Ito et al. (18). An exponentialphase culture $(200 \mathrm{ml})$ was washed with sterile $\mathrm{H}_{2} \mathrm{O}$ and suspended in $1 \mathrm{ml}$ of $10 \mathrm{mM}$ Tris hydrochloride- $0.1 \mathrm{M}$ lithium acetate-1 mM EDTA (pH 7.5) and incubated at $30^{\circ} \mathrm{C}$ with agitation for $1 \mathrm{~h}$. Samples of cells $(0.1 \mathrm{ml})$ were 
incubated with $40 \mu \mathrm{g}$ of sonicated carrier DNA (typically salmon sperm) and 5 to $10 \mu \mathrm{g}$ of transforming plasmid DNA at $30^{\circ} \mathrm{C}$ for $30 \mathrm{~min}$. Cells were then combined with $0.7 \mathrm{ml}$ of $40 \%$ polyethylene glycol $4000-0.1 \mathrm{M}$ lithium acetate- $10 \mathrm{mM}$ Tris hydrochloride-1 mM EDTA ( $\mathrm{pH} \mathrm{7.5)} \mathrm{and} \mathrm{incubated} \mathrm{for}$ $30 \mathrm{~min}$ at $30^{\circ} \mathrm{C}$. The cells were heat shocked at $42^{\circ} \mathrm{C}$ for 5 min, washed twice with $10 \mathrm{mM}$ Tris hydrochloride-1 $\mathrm{mM}$ EDTA $(\mathrm{pH} \mathrm{7.5)}(1 \times \mathrm{TE})$ and resuspended in $1 \mathrm{ml}$ of $1 \times \mathrm{TE}$, and samples $(0.2$ to $0.3 \mathrm{ml})$ were plated on selective medium.

Preparation and restriction digestion of yeast DNA. Yeast strains were grown overnight at $32^{\circ} \mathrm{C}$ in $10 \mathrm{ml}$ of YPD medium. The cells were harvested by centrifugation, washed once with $\mathrm{H}_{2} \mathrm{O}$, suspended in lysis buffer $(0.1 \mathrm{M}$ Tris hydrochloride [pH 8.0], $50 \mathrm{mM}$ EDTA, 1\% SDS), and transferred to Eppendorf tubes. Cells were lysed with glass beads by shaking on a Eppendorf Mixer 5432 for $15 \mathrm{~min}$ at $4^{\circ} \mathrm{C}$. The supernatant was transferred to a new tube and extracted with phenol and chloroform-isoamyl alcohol $(24: 1$, $\mathrm{vol} / \mathrm{vol})$. Nucleic acids were precipitated by the addition of $\mathrm{NaCl}$ to a final concentration of $0.5 \mathrm{M}$ and 2 volumes of ethanol and subsequently dissolved in STE ( $10 \mathrm{mM} \mathrm{NaCl}, 10$ $\mathrm{mM}$ Tris hydrochloride [ $\mathrm{pH} 8.0], 1 \mathrm{mM}$ EDTA). DNA samples were incubated in DNase-free-RNase A $(50 \mu \mathrm{g} / \mathrm{ml})$ for $1 \mathrm{~h}$ at $37^{\circ} \mathrm{C}$, extracted with chloroform-isoamyl alcohol, ethanol precipitated as described above, and dissolved in STE. Restriction endonuclease digestions were done as recommended by the supplier.

Gel electrophoresis and hybridization analysis of DNA. DNA samples were analyzed on $1.4 \%$ agarose slab gels containing $0.09 \mathrm{M}$ Tris borate ( $\mathrm{pH} \mathrm{8.3)}$ ) and $2.5 \mathrm{mM}$ EDTA (24). Transfer of DNA from agarose gels to nitrocellulose paper (BA 85; Schleicher \& Schuell) was performed essentially as described by Southern (32). Hybridization analysis was performed as described by Bloom and Carbon (4).

\section{RESULTS}

Transcription map of regions flanking the centromere in chromosome III. A physical map of the centromere region on chromosome III is shown in Fig. 1. Specific yeast DNA fragments from this region were isolated from recombinant plasmids and used as radiolabeled probes to measure the transcriptional activity of this region of the genome. RNA was analyzed from mitotic cultures of wild-type yeast cells grown to the mid-logarithmic phase in rich medium. RNA was extracted, separated by size on denaturing agarose gels, and transferred to nitrocellulose filters. RNA species visualized after hybridization and autoradiography are shown in Fig. 1. The most striking observation is the presence of RNA transcripts that occur within 200 to $300 \mathrm{bp}$ of the essential centromere core. Three overlapping transcripts, 1,300, 900, and 600 bases in length [ $(C E N 3) \mathrm{R} 1,-\mathrm{R} 2,-\mathrm{R} 3$, respectively] map 200 to 300 bp to the right of $C E N 3$, toward the $P G K$ gene (17). A single transcript, 800 bases in length [(CEN3)L], maps approximately 500 bp to the left of $C E N 3$, toward the $L E U 2$ gene (9). These transcripts are all retained on oligo(dT)-cellulose and thus contain poly $(\mathrm{A})^{+} 3^{\prime}$ ends or high stretches of deoxyadenylate in the transcript. The 1,300nucleotide RNA that maps $3 \mathrm{~kb}$ to the right of the centromere on chromosome III has been identified as the $C D C 10$ transcript (19). The amount of CDC10 mRNA has been measured by quantitative R-loop analysis to be about three to five copies per cell (E. Yeh and D. Kaback, unpublished data). In comparison, the (CEN3)R transcripts are present at less than one copy per cell, while $(C E N 3) \mathrm{L}$ transcripts are present at about one copy per cell. These tightly centromere-linked transcripts occur within the dis-

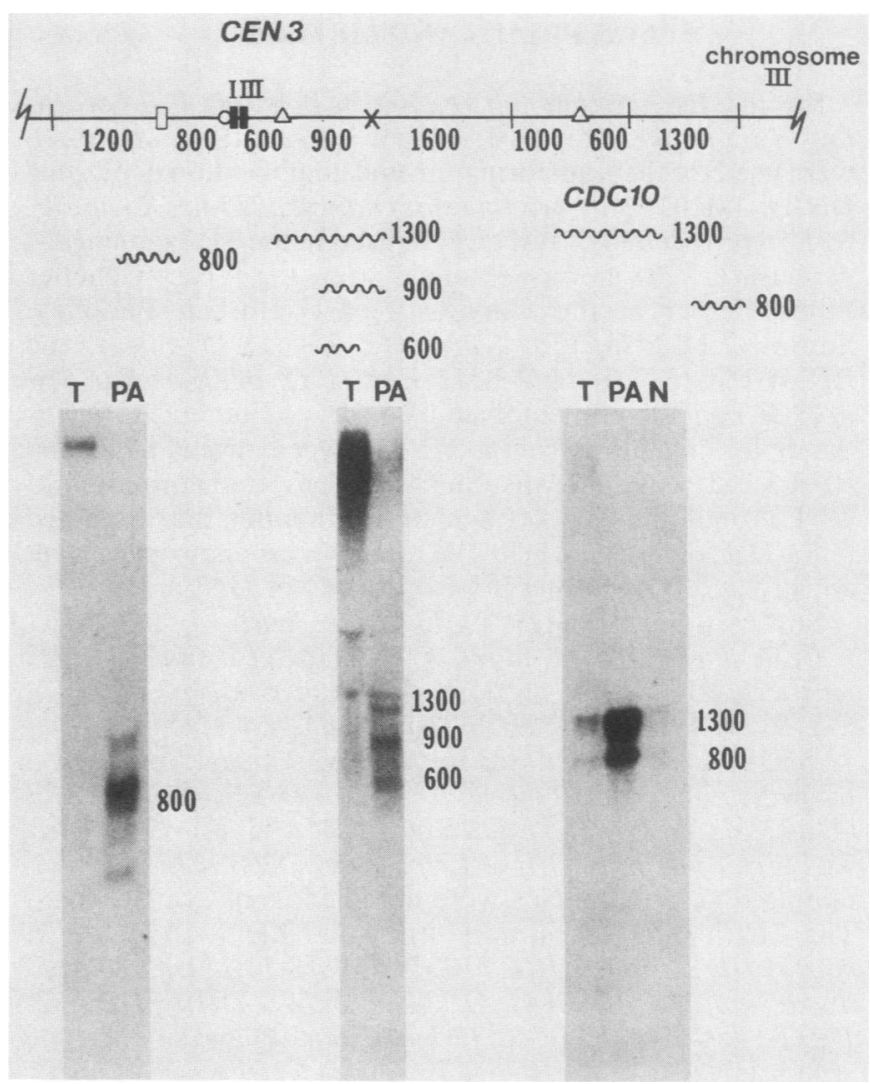

FIG. 1. Northern analysis of the centromere region of chromosome III. A physical map of the centromere region of chromosome III giving the location of the CEN3 element I to III region and the HindIII ( $\times$ ), ClaI ( $\square)$, BamHI ( $\triangle$ ), EcoRI (+), and selected Sau3A (O) restriction enzyme sites is shown above. The sizes of the restriction fragments are given below in base pairs. An 800-bp ClaI-Sau3A fragment, a 900-bp BamHI-HindIII fragment, and a 1,300-bp EcoRI fragment were used as hybridization probes in the RNA blots shown below (left to right, respectively). The wavy lines denote the relative positions of the RNA transcripts determined by the RNA gel blots shown below. The adjacent numbers refer to the sizes of the transcripts in nucleotides as determined by their migration on a denaturing $1.4 \%$ formaldehyde-agarose gel. $28 \mathrm{~S}$ rRNA and 18S rRNA were used as molecular weight standards. T, Total RNA; PA, poly(A) ${ }^{+}$RNA; N, nuclear RNA. Approximately $20 \mu \mathrm{g}$ of RNA was loaded per track.

tinct nucleosomal arrays flanking the centromere (see Fig. 3 [4]). No RNA was detected when 480 bp of $C E N 3$, including the conserved elements I to III, was used as a hybridization probe.

Transcriptional map of regions flanking the centromere on chromosome XI. We also investigated the transcriptional activity of the centromere region on chromosome XI. A physical map of the centromere region is shown in Fig. 2. The plasmid pYe(MET14)2 contains a $5.2-\mathrm{kb}$ yeast DNA insert that complements auxotrophic mutations in the MET14 gene on chromosome XI and demonstrates proper centromere function (14). pYe(MET14)2 DNA was digested with various restriction enzymes, and specific DNA fragments were isolated and used as hybridization probes to detect complementary RNA species as described above. Specific RNAs visualized after hybridization and autoradiography are shown in Fig. 2. A 2,200-base transcript, $(C E N 11) \mathrm{L}$, maps within $200 \mathrm{bp}$ of sequence element I to the left of $C E N 11$. The (CEN11)L transcript lies just outside the 


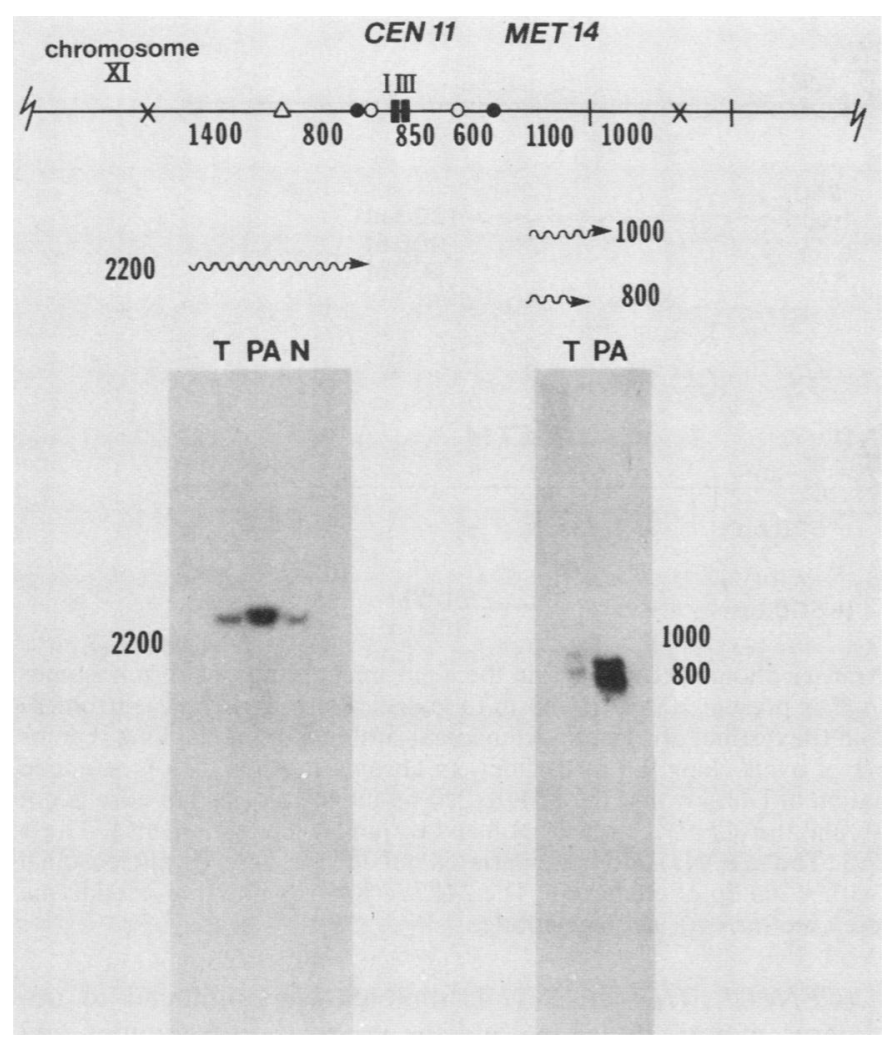

FIG. 2. Northern analysis of the centromere region of chromosome XI. A physical map of the centromere region of chromosome XI giving the location of the CENII element I to III region and the HindIII ( $\times$ ), BamHI $(\triangle)$, SalI (๑), EcoRI (+), and selected Sau3A $(O)$ restriction enzyme sites is shown above. The sizes of the restriction fragments are given below in base pairs. An 800-bp BamHI-SalI fragment (left) and a 1,100-bp SalI-EcoRI fragment (right) were used as hybridization probes on the RNA blots shown below. The wavy lines denote the relative map positions of the RNA transcripts, and the arrows mark the direction of transcription. The adjacent numbers refer to the sizes in nucleotides as determined by migration on a denaturing $1.4 \%$ formaldehyde-agarose gel. $28 \mathrm{~S}$ rRNA and 18S rRNA were used as molecular weight standards. T, Total RNA; PA, poly(A) ${ }^{+}$RNA; N, nuclear RNA. Approximately $20 \mu \mathrm{g}$ of RNA per track was loaded on each gel.

nuclease-hypersensitive site that demarcates the central centromere core and within the highly ordered nucleosomal array that extents $1.5 \mathrm{~kb}$ to the left of $C E N I 1$ (4) (see Fig. 3). Two transcripts 1,000 and 800 bases in length occur outside the ordered nucleosome region to the right of $C E N 11$, at the METI4 locus. The $(C E N 11) \mathrm{L}$ and METI4 transcripts are found in the poly $(\mathrm{A})^{+}$fraction of RNA and are present at approximately three to five copies per cell. The direction of transcription was determined by hybridization with singlestranded DNA isolated from M13 mp8 or M13 mp9 clones containing the $(C E N 11) \mathrm{L}$ or $M E T 14$ regions, respectively. The $(C E N 11) \mathrm{L}$ product is transcribed toward the centromere, and the METI4 transcript is transcribed away from the centromere. No RNAs unique to $C E N I I$ were detected when an 858-bp CENII Sau3A fragment was used as a hybridization probe.

The lack of detectable transcripts from the central centromere core in chromosomes III and XI suggests that the centromere core is a cis-acting sequence that does not encode structural or regulatory RNAs or proteins. The adjacent flanking sequences, characterized by distinct nucleosomal arrays extending 1 to $2 \mathrm{kbp}$ on either side of $C E N 3$ and $C E N I I$ (Fig. 3) are transcriptionally active. The proximity of transcribed genes to this essential region of the chromosome is surprising, since strong transcriptional promotors directed toward the centromere have been shown to interfere with centromere function in vivo. (25a; Hill and Bloom, unpublished data).

Disruption of the (CEN11)L transcript. The identification of transcriptional activity within 200 to $300 \mathrm{bp}$ of the central centromere core may simply reflect the efficient packing of genes along the chromatin fiber, or, if these centromerelinked transcripts are involved in chromosome segregation, it may reflect a relationship between chromosomal location and gene function. The transformation properties of yeasts allow one to disrupt gene sequences and effectively determine their role in essential cellular functions. Yeasts can be transformed with linear DNA molecules which recombine with homologous sites within the chromosome and thus replace the host chromosomal sequences (30). Therefore, in vitro sequence alterations can be constructed that, when used to replace the wild-type sequence, permit the in vivo function of the altered gene to be determined. We used this technique to disrupt the $(C E N I 1) \mathrm{L}$ transcript and determine its cellular function. The schematic diagram in Fig. 4 illustrates the transformation and substitution of the disrupted (CEN11)L fragment for the wild-type sequences in chromosome XI. HIS3/his3 diploids were obtained by transformation of the yeast strain UNC1 (see Materials and Methods) with the $(C E N I 1) \mathrm{L}$ disruption vector as described in the legend to Fig. 4. A diploid strain was chosen as the host for the gene disruption. If $(C E N I I) \mathrm{L}$ encodes an essential gene product, the inactivation of essential gene sequences would then be complemented by the other copy in the diploid host.

Substitution by the disruption fragment at the correct locus in the $\mathrm{HIS} 3^{+}$transformants was confirmed by hybridization of transformant DNA to radiolabeled cloned probes. DNA was isolated from the two haploid parents and two $\mathrm{HIS}^{+}$transformants. The DNA was restricted with EcoRI and $\mathrm{SalI}$, electrophoresed on a $1 \%$ agarose gel, transferred to nitrocellulose, and hybridized to a ${ }^{32} \mathrm{P}$-radiolabeled EcoRISall fragment encoding the (CENII)L transcript (Fig. 4). The resulting autoradiograph is shown in Fig. 5A. Lanes 1 and 2 are DNA samples isolated from the haploid parents $\left[(C E N 11) \mathrm{L}^{+}\right]$, and lanes 3 and 4 shows the $H I S 3^{+}$diploid transformants. Lanes 1 and 2 contain a 2.2-kb fragment reflecting the wild-type chromosome XI conformation. Lanes 3 and 4 contain the 2.2-kb fragment plus a $3.9-\mathrm{kb}$ fragment. The appearance of the $3.9-\mathrm{kb}$ fragment in the transformant strains is accounted for by insertion of the 1.7-kb HIS3 gene within the 2.2-kb (CENII)L gene. The equal intensity of the 2.2- and 3.9-kb bands indicates the heterozygous nature of the disruption.

To confirm that the $\mathrm{HIS3}^{+}$cells did not contain $(C E N 11) \mathrm{L}$ RNA, RNA was isolated from the transformant strains, separated by size on denaturing agarose gels, and transferred to nitrocellulose. (CENII)L transcripts were visualized after hybridization to radiolabeled (CENII)L DNA as described above. The autoradiograph shown in Fig. 5B confirms the absence of $(C E N I 1) \mathrm{L}$ RNA in $\mathrm{HIS3}^{+}$strains. The $(C E N 11) \mathrm{L}$ RNA was detectable in the wild-type haploid (lane 1), in the wild-type diploid (lane 3), and in diploids heterozygous for the $(C E N 11) \mathrm{L}$ disruption (lane 5). Both the haploid and the diploid homozygous disrupted strains contained no detectable (CEN11)L RNA (lanes 2 and 4). A diploid strain homozygous for the $(C E N I 1) \mathrm{L}$ disruption transformed with the plasmid pYe(MET14)2, containing the $(C E N I 1) \mathrm{L}$ gene, 

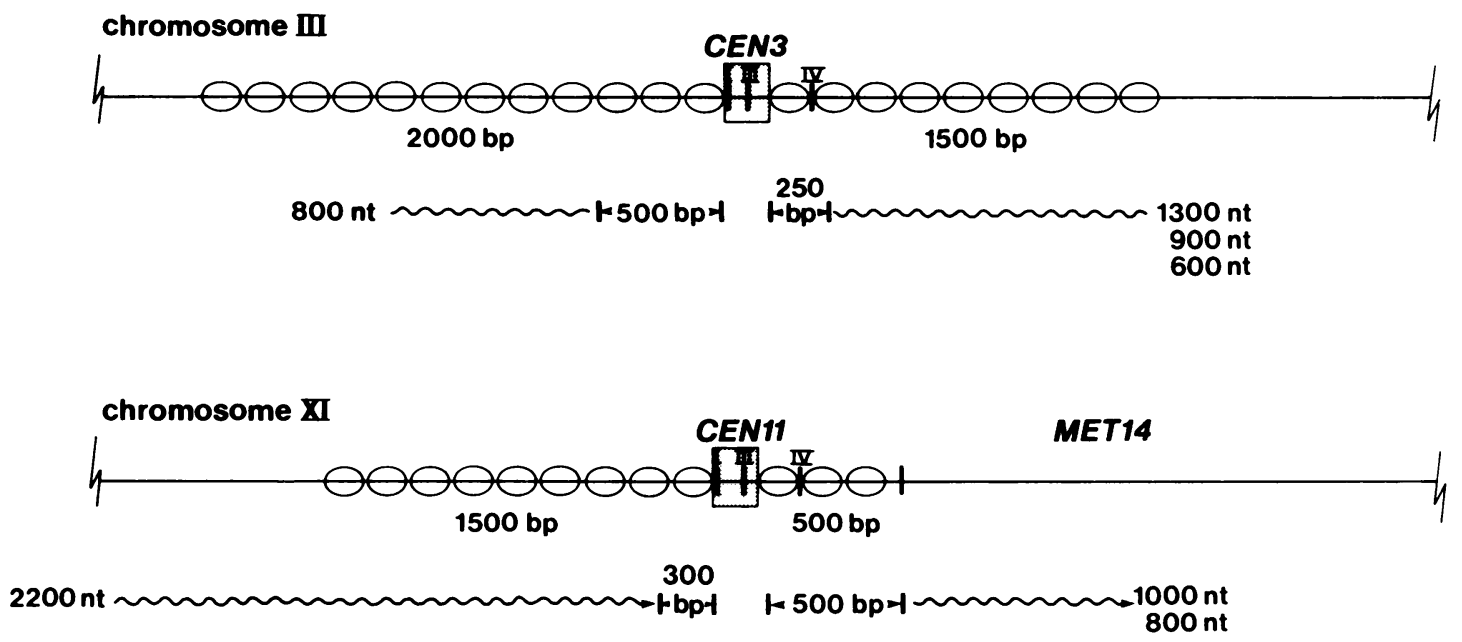

FIG. 3. Schematic representation of the structural organization and transcriptional activity within the centromere region of chromosomes III and XI. The DNA fiber from the region surrounding CEN3 and CENII is presented in linear form to visualize the protected centromere core (shaded box), including the conserved sequence elements I to III and the distinct arrays of nucleosomal subunits in the flanking regions (ovals). The extent of the nucleosomal arrays is depicted by the number of ovals along the DNA fiber. In chromatin, the DNA is wrapped around the histone core to form the nucleosomal subunit. The conformation of DNA within the 220- to 250-bp nuclease-resistant core is not shown. The (CEN3)R transcripts map within 200 to $300 \mathrm{bp}$ of element III, and the (CEN3)L transcript maps within $500 \mathrm{bp}$ of element I. These transcripts originate within the distinct nucleosomal arrays flanking CEN3. The (CEN11)L RNA is initiated outside the ordered nucleosomal region and is transcribed toward the centromere (arrow), terminating within $200 \mathrm{bp}$ of element I. The METI4 RNA is initiated outside the ordered nucleosome region and is transcribed away from the centromere core (arrow). nt, Nucleotide.

did contain the 2,200-base RNA (lane 6). The $(C E N 11) \mathrm{L}$ gene can therefore be expressed on an autonomously replicating plasmid.

Functional analysis of $(C E N 11) \mathrm{L}$ disrupted strains. We examined the role of this tightly centromere-linked gene, $(C E N 11) \mathrm{L}$, in mitotic or meiotic cell divisions. The
$(C E N 11) \mathrm{L}:: H I S 3 /(C E N 11) \mathrm{L}$ diploids were induced to undergo meiotic divisions, and the sporulation frequency and viability of the meiotic products were measured. There was no difference in the sporulation frequency between heterozygous diploids and the wild-type diploid ( 78 versus $80 \%$ ) (Table 1), and spore viability and growth rates were

chromosome XI

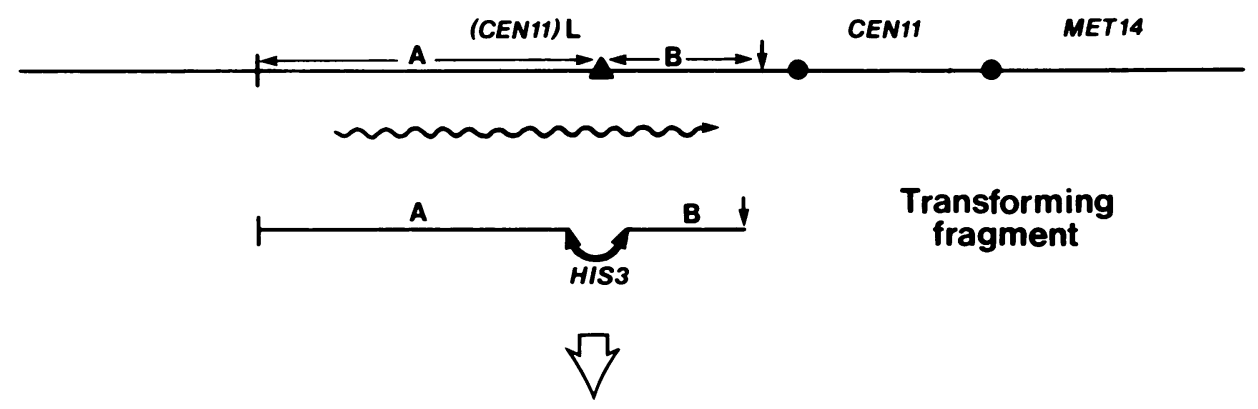

chromosome XI

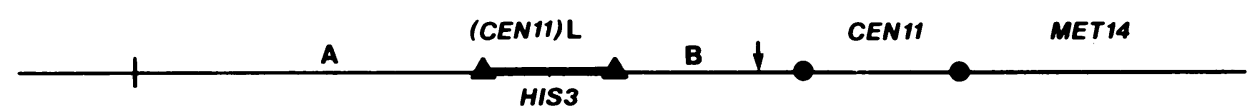

FIG. 4. Schematic representation of the centromere region of chromosome XI and the disruption of the (CENII)L gene. A physical map of the centromere region of chromsome XI gives the locations of $(C E N 11) \mathrm{L}, C E N 11$, and MET14. The (CEN11)L RNA is indicated below by the wavy line. Restriction sites are EcoRI (+), SalI ( $\downarrow)$, BamHI $(\Delta)$, and selected Sau3A sites ( $(\bullet)$. The 2,200-base (CENII)L transcript spans the 2.2-kb EcoRI-SalI fragment from chromosome XI. This fragment was cloned into EcoRI-SalI-digested pBR322, resulting in the plasmid $\mathrm{p}(C E N I I) \mathrm{L}$. To disrupt the coding sequences and have a selectable genetic marker, a 1.7-kb Bam HI fragment containing the HIS3 gene (34) was cloned into the unique BamHI site in the coding sequences of $(C E N 11) \mathrm{L}$. Restriction of the plasmid p $(C E N 11) \mathrm{LH}$ with EcoRI and SalI liberates the yeast sequences from pBR322. The transforming fragment contains the selectable marker HIS3 and the homologous regions $\mathrm{A}(1.4 \mathrm{~kb})$ and $\mathrm{B}(0.8 \mathrm{~kb})$. Transformation of the diploid strain UNC1 results in the chromosome XI conformation with the HIS3 gene disrupting the $(C E N 11) \mathrm{L}$ gene shown below. 


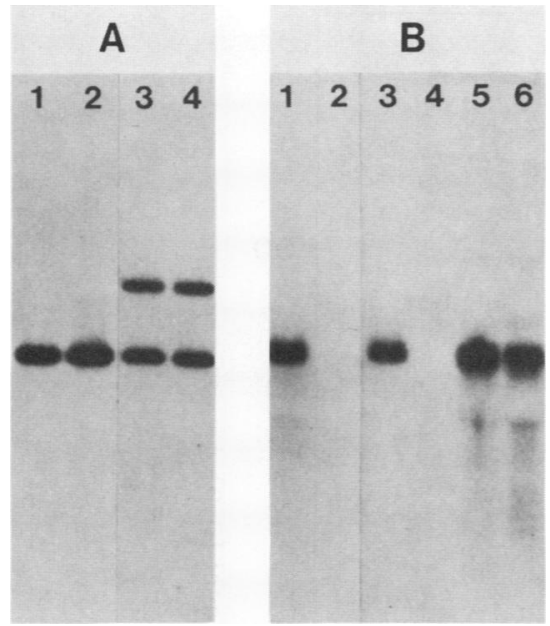

FIG. 5. Nucleic acid analysis of the (CEN11)L gene disruption. (A) Southern blot hybridization of total yeast DNAs from the wild-type parent haploids and $\mathrm{HIS3}^{+}$diploid transformants probed with the radiolabeled 2.2-kb EcoRI-SalI (CENII)L fragment. Total genomic DNA was restricted with EcoRI and SalI. Lanes 1 and 2 are the parent haploids LL20 and BF305-15D, respectively, and lanes 3 and 4 are the diploid $\mathrm{UNCl}$ transformed to the $H I S 3^{+}$phenotype with EcoRI-SalI-restricted p(CENII)LH (Fig. 4). (B) RNA blot hybridization of total yeast RNA probed with radiolabeled 2.2-kb EcoRI-SalI (CEN11)L DNA. Lanes: 1, nondisrupted haploid (his $\left.3^{-}\right) ; 2$, (CEN11)L disrupted haploid $\left(\mathrm{HIS3}^{+}\right)$; 3, wild-type diploid; 4, (CENII)L homozygous disrupted diploid; 5, diploid heterozygous for $(C E N 11) \mathrm{L} ; 6,(C E N I 1) \mathrm{L}$ homozygous disrupted diploid transformed with a plasmid, pYe $(M E T 14) 2$, containing the (CEN11)L gene (see Results section). The diploids containing a $(C E N 11) \mathrm{L}$ disruption were constructed by mating selected (CENII)L::HIS3 progeny.

also indistinguishable from those of the wild type (data not shown). Thus, the (CEN11)L gene is not essential for mitotic growth, and one copy is sufficient for diploids to undergo sporulation. Homozygous disruption strains were constructed by crossing the $F_{1}$ progeny of the disrupted diploid UNC1-2 (see Materials and Methods). The genotypes of the four (CEN11)L::HIS3/(CEN11)L::HIS3 strains constructed from different crosses and the percentage of sporulation are shown in Table 1 . No spores were formed in any of the diploid strains lacking a functional $(C E N 11) \mathrm{L}$ sequence. The inability to sporulate may not be related to the loss of the $(C E N 11) \mathrm{L}$ gene product but may result from the inherent mutagenicity of the transformation event itself or perhaps to the presence of HIS3 gene sequences adjacent to CENII. To determine whether the loss of the $(C E N 11) \mathrm{L}$ gene product is the cause of this phenotype, a cloned copy of the wild-type (CEN11)L gene was introduced into a yeast strain homozygous for the (CEN11)L disruption. Yeast strain UN2017 was transformed with the centromere plasmid pYe(MET14)2 containing the $(C E N 11) \mathrm{L}$ gene. (CEN11)L::HIS3/ (CEN11)L::HIS3 diploids containing the plasmid were able to sporulate, although at a slightly lower frequency than wild-type diploids. Approximately $60 \%$ of the cells formed two-, three-, and four-spored asci, consistent with the predicted number of cells that would contain the plasmid. The plasmid pYe(MET14)2 was present in only 60 to $70 \%$ of the cells after nonselective growth. If $(C E N 11) \mathrm{L}$ encodes a product essential for sporulation, then plasmid loss should result in the reversion to the sporulation-deficient phenotype. Single colonies that had lost $\mathrm{pYe}(M E T 14) 2$ were isolated after growth on nonselective medium and replica plated to media either containing or lacking tryptophan. Isogenic strains that differed only in the presence of pYe(MET14)2 were compared for their ability to sporulate. Diploids that maintained pYe(MET14)2 were able to sporulate, whereas diploids that had lost the plasmid were incapable of spore formation. This demonstrates that the $(C E N 11) \mathrm{L}$ gene product is trans acting and is essential for sporulation. We therefore named this gene SPOI5.

Temporal ordering of SPO15 in meiosis. During meiosis, DNA replication and recombination precede the first meiotic division, in which the homologous chromatids separate, but the sister chromatids remain paired. Sister chromatid separation analogous to a mitotic division does not occur until the second meiotic division. Selection schemes have been designed to isolate mutations in genes specific for sporulation (13). These mutant alleles include the spo (13), spd (12), and mei genes (29), and have helped elucidate the coordination of meiotic events. Diploids entering meiosis have a single unduplicated spindle pole body. These cells proceed through a round of premeiotic DNA synthesis and recombination, coincident with the duplication of the spindle pole bodies. Spindle pole body duplication and premeiotic DNA synthesis are independent events that can be separated by mutational analysis, but their completion is required for the first nuclear division of meiosis I. After the spindle pole bodies separate to form the spindle for meiosis I, they duplicate and separate again to form two meiotic II spindles.

To distinguish between a general metabolic defect that inhibits sporulation (13) and a specific meiotic gene function, the spols::HIS3 homozygous disrupted strains were grown on glucose, acetate, or glycerol as the carbon source. Growth rates of mutant and wild-type populations were

TABLE 1. Sporulation of (CEN11)L disrupted diploids ${ }^{a}$

\begin{tabular}{|c|c|c|c|}
\hline Strain & Genotype & $(C E N I I) \mathrm{L}$ & $\begin{array}{c}\% \\
\text { Sporulation }\end{array}$ \\
\hline UNC1 & $\begin{array}{l}\text { MATa/MAT } \alpha \text { his3-11,15/his3- } \\
11,15 \text { leu2-3,112/leu2-3,112 } \\
\text { adel/ADEI ADE2/ade2 arg5,6/ } \\
\text { ARG5,6 trpI/TRPI ura3-52/ } \\
\text { URA3 met14/METI4 }\end{array}$ & $+1+$ & 80 \\
\hline UN326 & 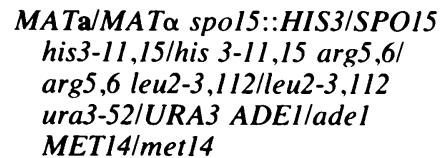 & $+1-$ & 78 \\
\hline UN614 & 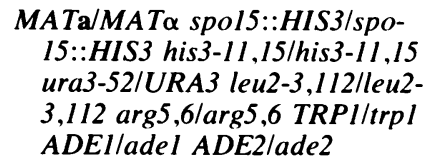 & $-1-$ & 0 \\
\hline UN2017 & 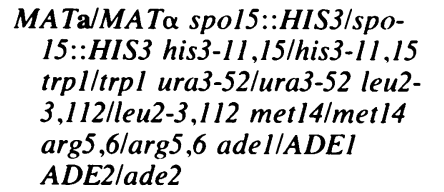 & $-1-$ & 0 \\
\hline UN4D & See Materials and Methods & $-1-$ & 0 \\
\hline UN4D4A & $\begin{array}{c}\text { MATa/MATa spol5::HIS3/spo- } \\
\text { 15::HIS3 his3-11,15/his3-11,15 } \\
\text { trp5-20/trp5-d ade2/ade2 urall } \\
\text { URA1 leu2-3,112/leu2-3,112 } \\
\text { LEU1/leul-12 LYS2/lys2-1 } \\
\text { TYRI/tyrl-I URA3/ura3-52 }\end{array}$ & $-1-$ & 0 \\
\hline
\end{tabular}

${ }^{a}$ Wild-type, heterozygous, and homozygous (CENII)L (spol5::HIS3) disrupted diploid strains were sporulated as described in the text. Ascus production was monitored microscopically. 


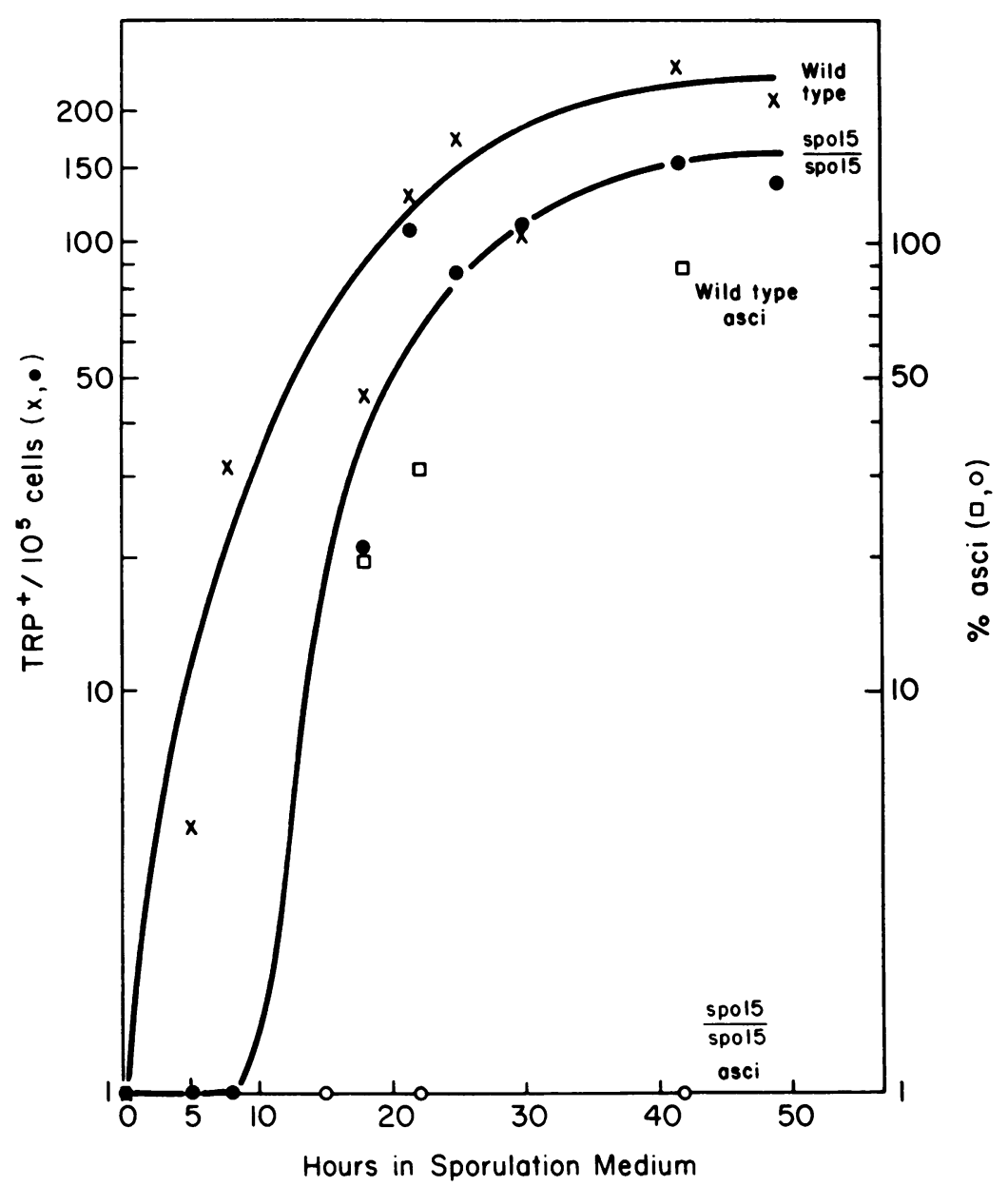

FIG. 6. Commitment to meiotic recombination in (CEN11)L homozygous disrupted diploids. Intragenic recombination at the trp5 locus was determined after exposure of UN4D and UN3C5C to sporulation medium. Cells withdrawn at the times indicated were plated on synthetic complete medium to assay viability and on medium lacking tryptophan to detect prototrophic intragenic recombinants. Prototroph values are given per number of CFU plated. Symbols: $\times$, wild-type UN3C5C;, spol5::HIS3/spol5::HIS3 UN4D. Ascus production was monitored by microscopic examination. Symbols: $\square$, UN3C5C; O, UN4D.

indistinguishable on each carbon source (data not shown). Thus, the requirement for spols in meiosis is not at the level of acetate utilization or mitochondrial function.

The commitment to sporulation can be measured in cells that have been induced to undergo the meiotic process and redirected toward mitotic growth when returned to rich medium during meiotic development. With increasing time in sporulation medium, the cells become irreversibly committed to the completion of meiosis and form haploid spores before resuming mitotic growth. The commitment to meiotic recombination is the time at which high levels of genetic recombination are detected after return to mitotic growth. We used this "return to growth" protocol (31) to determine whether the disrupted diploids were competent to undergo meiotic recombination and initiate the meiotic process. Intragenic recombination was measured by the increase in prototrophs when diploids heteroallelic for auxotrophic loci were plated on selective growth media after exposure to sporulation media. Yeast strains heteroallelic at the trp 5 locus were constructed to measure the commitment of cells to intragenic recombination (see above). The cells were grown in YPA medium to approximately $10^{7}$ cells per $\mathrm{ml}$ and suspended in 0.5 volume of $1 \%$ potassium acetate supplemented with amino acids. Samples of cells were taken every
$5 \mathrm{~h}$ and plated on synthetic complete medium with or without tryptophan to determine the number of viable cells and the percentage of $\operatorname{Trp}^{+}$prototrophs. The kinetics of intragenic recombination are shown in Fig. 6. In wild-type cells, tryptophan prototrophs in excess of the starting background were recovered about $5 \mathrm{~h}$ after introduction of the cells into sporulation medium. The yield of prototrophs continued to rise and reached a maximum at about $40 \mathrm{~h}$. About 200 prototrophs per $10^{5} \mathrm{CFU}$ were seen in the wild-type strain. Ascus production was monitored by microscopic examination, and approximately $80 \%$ of UN3C5C cells formed mature asci. The homozygous spols disruption strain also exhibited a commitment to meiotic recombination with intragenic recombination kinetics similar to that of wild-type cells. There was a slight lag with respect to the wild type when prototrophs in excess of the starting background first appeared, but the kinetics of prototroph production and the maximum number of prototrophs produced $\left(150 \mathrm{Trp}^{+}\right.$per $10^{5}$ CFU) were similar to wild-type levels. There was no significant loss of cell viability in either the wild-type or the spol5-disrupted cells.

The staining of DNA with the fluorescent compound diamidino-2-phenylindole dihydrochloride (DAPI) allows sporulating cells to be classified into several stages: 

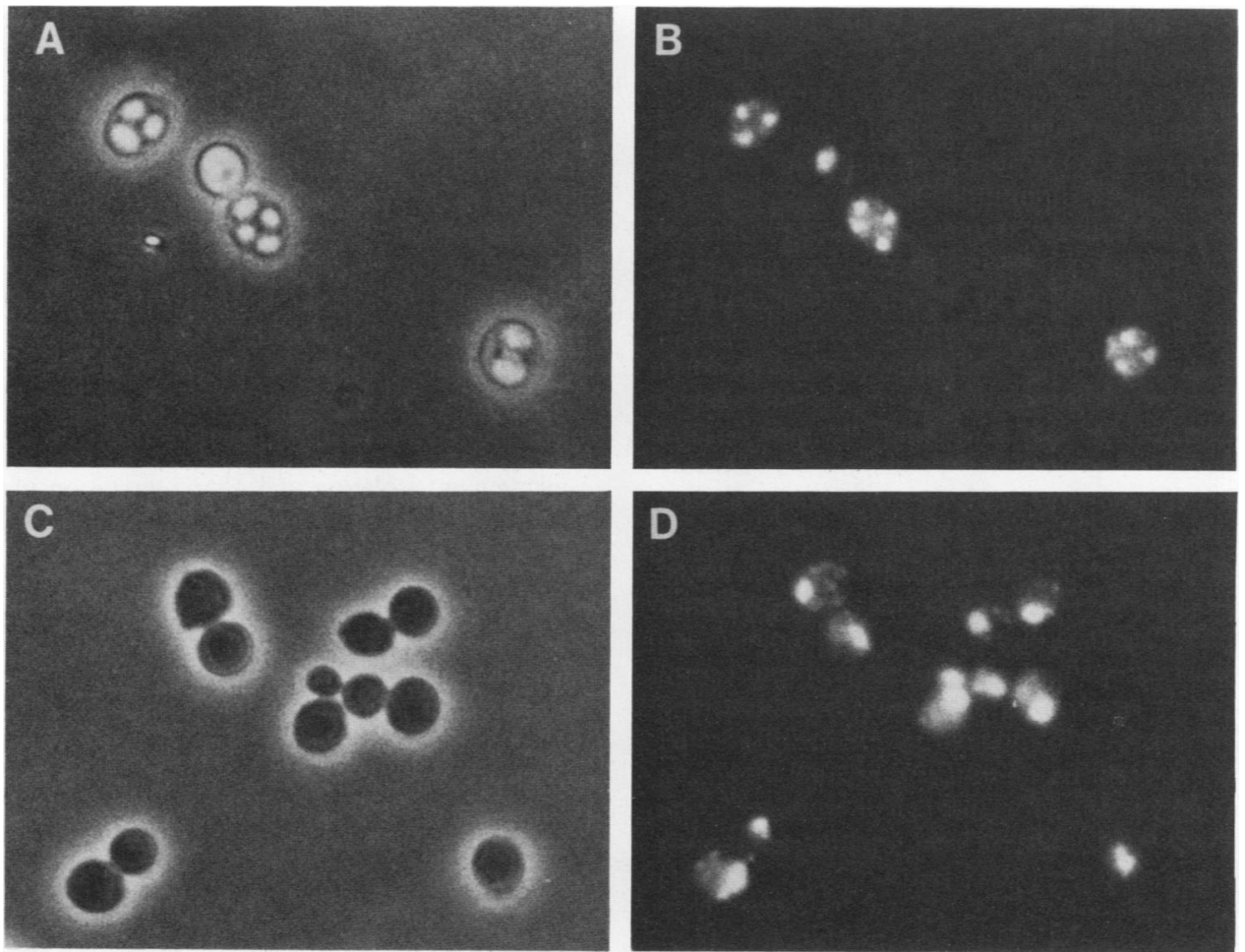

FIG. 7. DAPI staining of sporulated diploids. (A) Sporulating wild-type cells were stained after 4 days in sporulation medium with the fluorescent dye DAPI as described in the text. The photomicrograph was taken with phase optics. (B) The same cells viewed with fluorescence optics. Brightly staining dots in the cytoplasm represent mitochondrial DNA. (C) Sporulated homozygous disrupted diploids were stained with DAPI after 4 days in sporulation medium and photographed with phase optics. (D) The same cells viewed with fluorescence optics.

mononucleate, first nuclear division, binucleate, second nuclear division, and tetranucleate (37). We stained spols::HIS3/spol5::HIS3 diploids with DAPI to visualize at what meiotic stage the cells were arrested. Wild-type and spols::HIS3/spol5::HIS3 diploids were grown to the early logarithmic phase in presporulation, amino acid-supplemented YPA medium and then were suspended in sporulation medium. After 4 days of incubation at $32^{\circ} \mathrm{C}$, cells were stained with DAPI as described in Materials and Methods. Wild-type diploid cells stained with DAPI and visualized with phase optics revealed three and four spore asci per cell (Fig. 7A). When the same cells were visualized with fluorescent optics, nuclei were distinctly stained and corresponded to the number of spores seen in phase optics (Fig. 7B). Staining of the spols disrupted diploid cells revealed only cells in the mononucleate stage (Fig. 7D). After 4 days in sporulation medium the disrupted diploids became phasedark (Fig. 7C). The mononucleate nature of the disrupted diploids and the ability of the cells to undergo intragenic recombination suggests that the block in sporulation occurs immediately before or at the first meiotic nuclear division.

We examined the requirement for the SPOI5 gene product at later times in meiosis by utilizing another mutant gene, spol3-1, that bypasses meiosis I (20). In strains containing this mutation, meiotic recombination is followed by a single meiosis II-like division. The meiosis I reductional division is bypassed, and two diploid spores are formed. A spols spol3 double mutant was unable to complete any meiotic divisions. Staining of the mutant diploid cells with DAPI revealed a mononucleate staining pattern similar to that of spols disrupted diploids shown in Fig. 7C. The persistence of the spol5 mutant phenotype in the presence of the spol3 bypass suggests either that the function specified by SPOI5 is required for sporulation even after meiosis I or that SPO15 acts at a single time before the spol3-1 bypass occurs.

\section{DISCUSSION}

The centromere regions in the chromosomes from the yeast $S$. cerevisiae are the first eucaryotic centromeres to be characterized at the DNA sequence level. We used the centromere and centromere-flanking sequences as probes both for their molecular structure within the cell nucleus and for the transcriptional activity from this region of the genome (Fig. 3). Our findings revealed that the centromere region in yeasts is structurally distinct from the flanking chromosomal arms; however, repetitive satellite sequences that seem to be associated with the centromere in higher eucaryotes (27) are noticeably absent in this region of the yeast genome. A highly repeating array of nucleosomal subunits is characteristic of the flanking centromere region in chromosomes III and XI in yeasts (4) (Fig. 3). These structural subunits lie in a fixed position relative to the DNA sequence that abuts the centromere core and may be an evolutionary precursor to the structurally differentiated state seen in higher eucaryotes.

This flanking centromere region is also transcriptionally active in yeasts. RNA transcripts that map quite close to the centromere core (within 200 to $300 \mathrm{bp}$ ) were found in chromosomes III (Fig. 1), IV (33), and XI (Fig. 2). In no case were any transcripts detected that are homologous to the centromere core itself. These results indicate that the proximity of actively transcribed sequences near a centromere does not disrupt centromeric stabilization or segregation functions in vivo. However, when a centromere is placed 
downstream from a strong promoter, induction of the promoter can inactivate centromere function $(25 \mathrm{a}$; Hill and Bloom, unpublished data). A mechanism to prevent the transcriptional inactivation of the centromere from the endogenous transcripts would seem essential. The $(C E N 11) \mathrm{L}$ transcript we examined was transcribed toward the central centromere core, while other centromere-linked transcripts are transcribed away from the same centromere. Strong termination signals that abut the centromere core could prevent transcriptional readthrough and inactivation of the centromere. These presumptive termination signals could be specified by the DNA sequence or may result from structural parameters characteristic of the chromatin template. Alternatively, the promoter strength of centromere-proximal genes may prevent transcriptional inactivation of the centromere.

The ability to direct mutations into a specific region of the host chromosome allowed us to create a disruption mutation in the $(C E N 11) \mathrm{L}(S P O 15)$ transcriptional unit. This transcript was dispensable in mitosis but was absolutely required for meiotic cell division. The requirement for SPOI5 in meiosis but not mitosis was unrelated to the level of gene expression. The SPO15 gene is expressed during sporulation at approximately the same steady-state levels as in vegetative growth (38). The spols homozygotes are capable of intragenic recombination but arrest as mononucleate cells. This mutation, along with the previously characterized spol and spol0 genes (reviewed in reference 13), indicate that the commitment to DNA synthesis and meiotic recombination can be mutationally separated from the commitment to meiotic cell division. From a cytological point of view these results suggest that control of DNA metabolism is independent from the control of the segregation apparatus, i.e., spindle pole body duplication and spindle formation. A cytological analysis of spol and spolo illustrates that the spindle pole bodies remain unduplicated in these cells at the arrest point $(13,25)$. Furthermore, the $S P O I$ gene is required even after duplication of the spindle pole body in meiosis $I$. The SPO15 gene product may also be required for both the reductional and equational segregation divisions. Although there does not seem to be a correlation between the chromosomal location of genes and their function, two spo genes have also been mapped near centromeres, $S P O I$ on chromosome XIV and SPO7 on chromosome I. The SPO15 gene has not been previously characterized and is unique in its arrest in meiosis I (13). We have therefore identified a new gene product that is required at a specific stage in meiosis.

\section{ACKNOWLEDGMENTS}

We wish to thank Craig Giroux and Mike Resnick for many helpful discussions and Larry Schwartz for critical reading of the manuscript.

This work was supported by Public Health Service grants GM-32258 (to K.S.B.) and CA-11034 (to J.C.) from the National Institutes of Health.

\section{LITERATURE CITED}

1. Baker, B. S. 1958. Crossing over in heterochromatin. Am. Nat. 92:59-60.

2. Becker, H. J. 1976. Mitotic recombination, p. 1020-1089. In M. Ashburner and E. Novitski (ed.), The genetics and biology of Drosophila, vol. 1C. Academic Press, Inc. (London), Ltd., London.

3. Bloom, K., E. Amaya, J. Carbon, L. Clarke, A. Hill, and E. Yeh. 1984. Chromatin conformation of yeast centromeres. J. Cell Biol. 99:1559-1568.
4. Bloom, K., and J. Carbon. 1982. Yeast centromere DNA is in a unique and highly ordered structure in chromosomes and small circular minichromosomes. Cell 29:305-317.

5. Bloom, K., M. Fitzgerald-Hayes, and J. Carbon. 1983. Structural analysis and sequence organization of yeast centromeres. Cold Spring Harbor Symp. Quant. Biol. 47:1175-1185.

6. Cameron, J. R., E. Y. Loh, and R. W. Davis. 1979. Evidence for the transposition of dispersed repetitive DNA families in yeast. Cell 16:739-751.

7. Carbon, J. 1984. Yeast centromeres: structure and function. Cell 37:351-353.

8. Carbon, J., and L. Clarke. 1984. Structural and functional analysis of a yeast centromere $(C E N 3)$. J. Cell Sci. 1 (Suppl.):43-58.

9. Chinault, A. C., and J. Carbon. 1979. Overlap hybridization screening: isolation and characterization of overlapping DNA fragments surrounding the leu2 gene on yeast chromosome III. Gene 5:111-126.

10. Clarke, L., and J. Carbon. 1980. Isolation of a yeast centromere and construction of small circular minichromosomes. Nature (London) 287:504-509.

11. Clarke, L., and J. Carbon. 1983. Genomic substitution of centromeres in Saccharomyces cerevisiae. Nature (London) 305:23-28.

12. Dawes, I. W. 1975. Study of cell development using derepressed mutations. Nature (London) 255:707-708.

13. Esposito, R. E., and S. Klapholz. 1981. Meiosis and ascospore development, p. 211-287. In J. N. Strathern, E. W. Jones, and J. R. Broach (ed.), The molecular biology of the yeast Saccharomyces cerevisiae. Life cycle and inheritance. Cold Spring Harbor Laboratory, Cold Spring Harbor, N.Y.

14. Fitzgerald-Hayes, M., J.-M. Buhler, T. G. Cooper, and J. Carbon. 1982. Isolation and subcloning analysis of functional centromere DNA from Saccharomyces cerevisiae chromosome XI. Mol. Cell. Biol. 2:82-87.

15. Fitzgerald-Hayes, M., L. Clarke, and J. Carbon. 1982. Nucleotide sequence comparisons and functional analysis of yeast centromere DNAs. Cell 29:235-244.

16. Garcia-Bellido, A. 1972. Parameters of mitotic recombination. Mol. Gen. Genet. 115:54-72.

17. Hitzeman, R. A., L. Clarke, and J. Carbon. 1980. Isolation and characterization of the yeast 3-phosphoglycerokinase gene $(P G K)$ by an immunological screening technique. J. Biol. Chem. 255:12073-12080.

18. Ito, H., Y. Fukuda, K. Murata, and A. Kimura. 1983. Transformation of intact yeast cells treated wtih alkali cations. J. Bacteriol. 153:163-168.

19. Kaback, D. B., and L. R. Feldberg. 1984. Saccharomyces cerevisiae exhibits a sporulation-specific temporal pattern of transcript accumulation. Mol. Cell. Biol. 5:751-761.

20. Klapholy, S., and R. E. Esposito. 1980. Isolation of SPO12-1 and SPO13-1 from a natural variant of yeast that undergoes a single meiotic division. Genetics 96:567-588.

21. Lewis, E. B. 1950. The phenomenon of position effect. Adv. Genet. 3:75-115.

22. Maine, G. T., R. T. Surosky, and B.-K. Tye. 1984. Isolation and characterization of the centromere from chromosome V (CEN5) of Saccharomyces cerevisiae. Mol. Cell. Biol. 4:86-91.

23. Malone, R. E., J. E. Golin, and M. S. Esposito. 1980. Mitotic versus meiotic recombination in Saccharomyces cerevisiae. Curr. Genet. 1:241-248.

24. Maniatis, T., E. F. Fritsch, and J. Sambrook. 1982. Molecular cloning, a laboratory manual. Cold Spring Harbor Laboratory, Cold Spring Harbor, N.Y.

25. Moens, P. B., R. E. Esposito, and M. S. Esposito. 1974. Aberrant nuclear behavior at meiosis and anucleate spore formation by sporulation-deficient (SPO) mutants of Saccharomyces cerevisiae. Exp. Cell Res. 83:166-174.

25a.Panzeri, L., I. Groth-Clausen, J. Shepard, A. Stotz, and P. Philippsen. 1984. Centromeric DNA of yeast, p. 46-58. In A. Gropp, M. D. Bennett, and V. Wolf (ed.), Chromosome today, vol. 8. George Allen and Union, London. 
26. Panzeri, L., and P. Philippsen. 1982. Centromeric DNA from chromosome VI in Saccharomyces cerevisiae strains. Eur. Mol. Biol. Organ. 1:1605-1611.

27. Pardue, M. L., and J. G. Gall. 1970. Chromosomal localization of mouse satellite DNA. Science 168:1356-1358.

28. Reed, S. I., J. Ferguson, and J. C. Groppe. 1982. Preliminary characterization of the transcriptional and translational products of the Saccharomyces cerevisiae cell division cycle gene CDC28. Mol. Cell. Biol. 2:412-425.

29. Roth, R. 1973. Chromosome replication during meiosis: identification of gene functions required for premeiotic DNA synthesis. Proc. Natl. Acad. Sci. USA 70:3087-3091.

30. Rothstein, R. J. 1983. One-step gene disruption in yeast. Methods Enzymol. 101:202-211.

31. Sherman, F., and H. Roman. 1963. Evidence for two types of allelic recombination in yeast. Genetics 48:255-261.

32. Southern, E. M. 1975 . Detection of specific sequences among DNA fragments separated by gel electrophoresis. J. Mol. Biol. 98:503-517.

33. Stinchcomb, D. T., C. Mann, and R. W. Davis. 1982. Centromere DNA from Saccharomyces cerevisiae. J. Mol. Biol.
158:157-179.

34. Struhl, K., and R. W. Davis. 1980. A physical, genetic and transcription map of the cloned his 3 gene region of Saccharomyces cerevisiae. J. Mol. Biol. 136:309-332.

34a.Struhi, K., D. T. Stinchcomb, S. Scherer, and R. W. Davis. 1979. High-frequency transformation of yeast: autonomous replication of hybrid DNA molecules. Proc. Natl. Acad. Sci. USA 76:1035-1039.

35. Thomas, P. S. 1980. Hybridization of denatured RNA and small DNA fragments transferred to nitrocellulose. Proc. Natl. Acad. Sci. USA 77:5201-5205.

36. Tschumper, G., and J. Carbon. 1983. Copy number control by a yeast centromere $(C E N)$. Gene 23:221-232.

37. Williamson, D. H., and D. J. Fennell. 1975. The use of fluorescent DNA-binding agent for detecting and separating yeast mitochondrial DNA. Methods Cell Biol. 12:335-351.

38. Yeh, E., and K. Bloom. 1985. Structure and functional analysis of the centromere region in yeast, p. 231-242. In V. VaughanDellarco, P. Voytek, and A. Hollaender (ed.), Symposium on Aneuploidy: Etiology and Mechanisms. Plenum Publishing Corp., New York. 